\title{
Cytokine treatment optimises the immunotherapeutic effects of umbilical cord-derived MSC for treatment of inflammatory liver disease
}

Samantha F. H. de Witte ${ }^{1 *}$, Ana M. Merino ${ }^{1}$, Marcella Franquesa ${ }^{1}$, Tanja Strini ${ }^{1}$, Johanna A. A. van Zoggel ${ }^{2}$, Sander S. Korevaar ${ }^{1}$, Franka Luk1, Madhu Gargesha ${ }^{5}$, Lisa O'Flynn ${ }^{3}$, Debashish Roy ${ }^{5}$, Steve J. Elliman ${ }^{3}$,

Philip N. Newsome ${ }^{4}$, Carla C. Baan ${ }^{1}$ and Martin J. Hoogduijn ${ }^{1}$

\begin{abstract}
Background: Mesenchymal stromal cells (MSC) possess immunomodulatory properties and low immunogenicity, both crucial properties for their development into an effective cellular immunotherapy. They have shown benefit in clinical trials targeting liver diseases; however the efficacy of MSC therapy will benefit from improvement of the immunomodulatory and immunogenic properties of MSC.

Methods: MSC derived from human umbilical cords (UCMSC) were treated for 3 days in vitro with various inflammatory factors, interleukins, vitamins and serum deprivation. Their immunogenicity and immunomodulatory capacity were examined by gene-expression analysis, surface-marker expressions, IDO activity, $\mathrm{PGE}_{2}$ secretion and inhibition of $\mathrm{T}$ cell proliferation and IFNY production. Furthermore, their activation of NK cell cytotoxicity was investigated via CD107a expression on NK cells. The immunomodulatory capacity, biodistribution and survival of pre-treated ucMSC were investigated in a $\mathrm{CCl}_{4}$-induced liver disease mouse model. In addition, capacity of pre-treated MSC to ameliorate liver inflammation was examined in an ex vivo liver inflammation co-culture model.

Results: IFN- $\gamma$ and a multiple cytokine cocktail (MC) consisting of IFN- $\gamma$, TGF $\beta$ and retinoic acid upregulated the expression of immunomodulatory factor PD-L1 and IDO activity. Subsequently, both treatments enhanced the capacity of ucMSC to inhibit CD4 and CD8 T cell proliferation and IFN- $\gamma$ production. The susceptibility of uCMSC for NK cell lysis was decreased by IFN- $\beta$, TGF $\beta$ and MC treatment. In vivo, no immunomodulation was observed by the uCMSC. Four hours after intravenous infusion in mice with $\mathrm{CCl}_{4}$-induced inflammatory liver injury, the majority of ucMSC were trapped in the lungs. Rapid clearance of ucMSC(VitB $\left.\left.)_{6}\right), \mathrm{uCMSC}_{\mathrm{C}} \mathrm{Starv}+\mathrm{VitB}_{6}\right)$ and UCMSC(MC) and altered bio-distribution of UCMSC(TGF $\beta$ ) compared to untreated uCMSC was observed. In the ex vivo co-culture system with inflammatory liver slices ucMSC(MC) showed significantly enhanced modulatory capacity compared to untreated UCMSC.
\end{abstract}

Conclusions: The present study demonstrates the responsiveness of ucMSC to in vitro optimisation treatment. The observed improvements in immunomodulatory capacity as well as immunogenicity after MC treatment may improve the efficacy of UCMSC as immunotherapy targeted towards liver inflammation.

Keywords: Immunogenic, Immunomodulatory, Mesenchymal stromal cell, Optimising

\footnotetext{
* Correspondence: s.dewitte@erasmusmc.nl

${ }^{1}$ Nephrology and Transplantation, Department of Internal Medicine, Erasmus

MC, Postbus 20403000 CA Rotterdam, The Netherlands

Full list of author information is available at the end of the article
} 


\section{Background}

Mesenchymal stromal cells (MSC) are a novel therapeutic option for inflammatory conditions and have been studied in animal models as well as in preliminary clinical studies [1-6]. In particular, MSC have shown potential in clinical trials of patients with liver diseases, such as liver cirrhosis [7-10] and acute-on-chronic liver failure [11-13]. In addition, they have shown to be able to modulate the immune system in other various diseases, however, there is not convincing evidence for all diseases [1]. MSC possess two immunological properties that make them interesting candidates for cellular immunotherapy; their immunomodulatory capacity and low recognition by the host immune system. Optimisation of these properties will enhance their efficacy as immunotherapy.

MSC express a vast range of factors which target immune cells and influence their function, such as modulation of B cell and natural killer (NK) cell function, suppression of $\mathrm{T}$ cell proliferation/activation as well as induction of regulatory T cells (Treg) [14-17]. One of their key immunomodulatory factors is indoleamine 2,3-dioxygenase (IDO), which deprives the environment of L-tryptophan thereby inhibiting lymphocyte proliferation [18], has been demonstrated to promote graft acceptance after solid organ transplantation [19]. In addition, prostaglandin $\mathrm{E}_{2}\left(\mathrm{PGE}_{2}\right), \mathrm{CCL} 2$ and interleukin 1 receptor antagonist (IL1RA), which are produced by MSC have shown to have an important role in the therapeutic effects of MSC on autoimmune diseases, such as rheumatoid arthritis [3, 4, 20-23]. Besides secretion of anti-inflammatory factors, MSC express cell surface proteins that are known for their immunoregulatory function, such as programmed death-ligand 1 (PDL1), which inhibits lymphocyte proliferation [24].

In addition, MSC have low immunogenicity due to low levels of HLA class I and lack of HLA class II and costimulatory molecule expression on their surface, which may potentially allow the use of allogeneic MSC for treatment without inducing allogeneic responses [25]. In addition, complex formation of HLA class I with inhibitory NK cell receptors protects MSC from NK cell lysis [26]. However, HLA class I enables recognition of MSC by allogenic $\mathrm{CD}^{+} \mathrm{T}$ cells, and initiation of lysis [26, 27] and Cho et al. observed IgG antibody responses to allogeneic umbilical cord tissue-derived stromal cells [28]. Consequently, recognition by immune cells in vivo may reduce the survival time of MSC and thereby restricting the duration of their effect [29]. Another in vivo drawback is that MSC get trapped in the lungs due to their size, restricting their migration to the site of injury $[29,30]$. Improving MSC ex vivo in such a way that their immunogenicity is reduced and their immunosuppressive capacity is enhanced may therefore be beneficial for their survival as well as their effectiveness after administration.
MSC can be isolated from different tissues in the body [31], and often constitute a heterogeneous population of cells. The use of a more homogeneous MSC subset, will potentially increase the consistency of treatment results and improve efficacy. Studies involving specific MSC subsets, based on selection of MSC expressing Stro-1, CD73, CD90 or CD271, have shown that these subsets possess enhanced immunosuppressive capacities [32-36]. Recently, a new subset, identified by the surface marker CD362 ${ }^{+}$(Syndecan-2) has been identified (patent number WO 2013117761 A1), which showed improved clonogenicity and immunomodulatory properties.

MSC contain an abundance of surface receptors for a large variety of factors such as inflammatory factors, interleukins, prostaglandins and several vitamins. Treatment of MSC by such factors, like interferon gamma (IFN- $\gamma$ ), tumour necrosis factor alpha (TNF- $\alpha$ ) and interleukin 17 (IL-17), induces MSC to adapt towards a more immunomodulatory phenotype and alters their immunogenicity [37-39]. In addition, different culture conditions, such as serum-deprivation and hypoxia [40] may affect the function of MSC.

In this study, we exposed MSC to various growth factors, cytokines and culture conditions with the aim to generate MSC with enhanced properties; reduced immunogenicity and improved immunosuppressive capacity, for immunotherapy to target liver inflammation. Through analysing surface marker expression, gene expression and secretome we examined the immunophenotype of pretreated MSC. In addition, the immunogenicity and immunomodulatory capacity of pre-treated MSC were evaluated by their susceptibility to trigger NK cytotoxic activity and their capacity to inhibit lymphocyte proliferation, respectively. Furthermore, their potential to ameliorate inflammation and immunomodulate the immune response was tested in vivo as well as ex vivo in a murine liver inflammation model.

\section{Methods}

\section{Culture expansion of ucMSC}

Human umbilical cord tissue was collected from Caesarean section deliveries by Tissue Solutions Ltd. (Glasgow, UK) from virally screened healthy donors. All such cord was obtained according to legal and ethical requirements of the UK, with the approval of the relevant ethics committee and with anonymous consent from the donor. Cords were harvested within 48 hours of birth and the average length of collected umbilical cord tissue $(\mathrm{n}=4-6)$ was $8.6 \mathrm{~cm}$, with all tissues transported for processing to Orbsen Therapeutics Ltd. in $\mathrm{AQIX}^{\oplus}$ solution (London, UK) at $4{ }^{\circ} \mathrm{C}$. In short, umbilical cord tissue was washed and the whole tissue was manually dissociated before enzymatic digestion in an enzyme cocktail consisting of MEM alpha (Gibco, Thermo 
Fisher Scientific, Paisley, UK), collagenase 1 (2 mg/ml), hyaluronidase $1(1 \mathrm{mg} / \mathrm{ml})$ and DNase $(0.1 \mathrm{mg} / \mathrm{ml})$ (SigmaAldrich, Arklow, Ireland) for a maximum of 2 hours at $37^{\circ}$ C. Thereafter, a single cell suspension was obtained by filtration $(100 \mu \mathrm{m})$ and the cells were stained with CD362 (Syndecan-2/ORB, APC, clone 305515, dilution 1:50, R\&D Systems, Minneapolis, MN, USA) for 30 minutes at $4{ }^{\circ} \mathrm{C}$. Subsequently, cells were washed and resuspended in MACs buffer $80 \mu \mathrm{l} / 10^{7}$ cells. Next, the cells were incubated with anti-APC beads $\left(20 \mu \mathrm{l} / 10^{7}\right.$ cells, Miltenyi Biotec, $\mathrm{GmbH}$, Bergisch Gladbach, Germany) for 15 minutes at $4{ }^{\circ} \mathrm{C}$. $\mathrm{CD} 62^{+}$cells were then isolated using MS MACs column according to manufacturer's instructions, (Miltenyi Biotec). Each cell fraction was counted, seeded for expansion and cryopreserved at passage 2 for shipment to Erasmus Medical Center. Here ucMSC were cultured in minimum essential medium Eagle alpha modification (MEM- $\alpha$; Sigma-Aldrich, St. Louis, MO, USA) containing $2 \mathrm{mM} \mathrm{L-}$ glutamine (Lonza, Verviers, Belgium), 1\% penicillin/streptomycin solution (P/S; $100 \mathrm{IU} / \mathrm{ml}$ penicillin, $100 \mathrm{IU} / \mathrm{ml}$ streptomycin; Lonza) and supplemented with $15 \%$ fetal bovine serum (FBS; Lonza) and $1 \mathrm{ng} / \mathrm{ml}$ basic fibroblast growth factor (bFGF) (Sigma-Aldrich) and kept at $37{ }^{\circ} \mathrm{C}$, $5 \% \mathrm{CO}_{2}$ and $20 \% \mathrm{O}_{2}$. Medium was changed once a week and ucMSC were passaged at approximately $80-90 \%$ confluence using $0.05 \%$ trypsin-EDTA (Life Technologies, Paisley, UK). All ucMSC used in experiments were between passage 4 and 7.

\section{Study design}

A set of in vitro, in vivo and ex vivo experiments was designed to analyse the effect of pre-treatment of ucMSC with various growth factors, cytokines and culture conditions, as depicted in Additional file 1: Figure S1 and described in detail below.

\section{Treatment of ucMSC}

UcMSC were treated with (Table 1 and Additional file 2: Table S1): activin A (12 ng/ml; Miltenyi Biotec $\mathrm{GmbH})$, budesonide (50 mM; FLUKA Sigma-Aldrich), interferon gamma (IFN- $\gamma, 50 \mathrm{ng} / \mathrm{ml}$; Life Technologies), interferon beta (IFN- $\beta, 5 \mathrm{ng} / \mathrm{ml}$; Peprotech, Rocky Hill, NJ, USA), transforming growth factor beta 1 (TGF $\beta, 10 \mathrm{ng} / \mathrm{ml}$; R\&D Systems), interleukin-15 (IL-15, $10 \mathrm{ng} / \mathrm{ml}$; Peprotech), interleukin-17 (IL-17, $50 \mathrm{ng} / \mathrm{ml}$; Peprotech), retinoic acid (RA, $1 \mu \mathrm{M}$ and $10 \mu \mathrm{M}$; Sigma), trespostinil (20 ng/ml; Cayman Chemical Company, Ann Arbor, MI, USA), tumour necrosis factor alpha (TNF- $\alpha, 10 \mathrm{ng} / \mathrm{ml}$; Peprotech), $1 \alpha, 25$-dihydroxyvitamin $\mathrm{D}_{3}$ (vitamin $\mathrm{D}_{3}$, $\mathrm{VitD}_{3} ; 0.01 \mu \mathrm{M}$; Sigma-Aldrich) and pyridoxal hydrochloride (vitamin $\mathrm{B}_{6}, \mathrm{Vit}_{6}, 1 \mu \mathrm{M}$; Sigma-Aldrich). All factors were added at day 0 and the cells were analysed at day 3, except for trespostinil, which due to its instability was added daily. In addition, ucMSC were also cultured without serum (starvation, Starv). Two further combinations were also used: starvation and vitamin $\mathrm{B}_{6}$ $\left(\mathrm{Starv}+\mathrm{VitB}_{6}\right)$ and the multiple cytokine combination $(\mathrm{MC})$, consisting out of IFN- $\gamma$, TGF $\beta$ and RA.

\section{Flow cytometric analysis}

Flow cytometric characterisation of control and treated ucMSC was performed by labelling with standard MSC markers, according to ISSCT criteria [41]: CD13 (PE-

Table 1 Observed changes in immunogenic and immunomodulatory molecules after 3 days in vitro treatment of ucMSC

\begin{tabular}{|c|c|c|c|c|c|c|c|}
\hline & \multicolumn{2}{|c|}{ Immunogenic read out parameters } & \multicolumn{4}{|c|}{ Immunomodulatory read out parameters } & \multirow{2}{*}{$\begin{array}{l}\text { Fold increase of gene expression } \\
\text { compared to unstimulated } \\
\text { IL-1RA [corrected for GAPDH] }\end{array}$} \\
\hline & $\begin{array}{l}\text { HLA class } \\
\text { I- expressing } \\
\text { cells [\%] }\end{array}$ & $\begin{array}{l}\text { HLA class } \\
\text { II- expressing } \\
\text { cells [\%] }\end{array}$ & 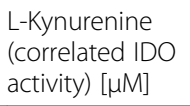 & $\begin{array}{l}\mathrm{PGE}_{2} \\
{[\mathrm{ng} / \mathrm{ml}]}\end{array}$ & $\begin{array}{l}\text { PD-L1- expressing } \\
\text { cells [\%] }\end{array}$ & $\begin{array}{l}\text { CD73-expressing } \\
\text { cells [\%] }\end{array}$ & \\
\hline$[-]$ & $7 \pm 1$ & $10 \pm 3$ & $2 \pm 5$ & $14 \pm 3$ & $46 \pm 6$ & $95 \pm 2$ & $1 \pm 0$ \\
\hline IFN-y & $60 \pm 9^{*}$ & $68 \pm 9^{*}$ & $27 \pm 10^{*}$ & $1 \pm 0^{*}$ & $95 \pm 3^{*}$ & $94 \pm 3$ & $1 \pm 0$ \\
\hline IFN- $\beta$ & $36 \pm 12^{*}$ & $14 \pm 5$ & $10 \pm 10$ & $3 \pm 2$ & $73 \pm 12$ & $91 \pm 5$ & $4 \pm 1$ \\
\hline TGF $\beta$ & $9 \pm 3$ & $10 \pm 3$ & $3 \pm 1$ & $3 \pm 2$ & $58 \pm 7$ & $89 \pm 5$ & $4 \pm 4$ \\
\hline Starv & $15 \pm 3^{*}$ & $4 \pm 2$ & $6 \pm 3$ & $4 \pm 3$ & $24 \pm 8^{*}$ & $100 \pm 0$ & $1 \pm 0$ \\
\hline $\mathrm{VitB}_{6}$ & $47 \pm 5^{*}$ & $34 \pm 9^{*}$ & $3 \pm 5$ & $12 \pm 5$ & $59 \pm 14$ & $100 \pm 0$ & $67 \pm 42$ \\
\hline Starv + VitB 6 & $62 \pm 7^{*}$ & $22 \pm 5^{*}$ & $0 \pm 3$ & $6 \pm 3$ & $72 \pm 7^{*}$ & $100 \pm 0$ & $507 \pm 262$ \\
\hline RA & $26 \pm 5^{*}$ & $18 \pm 5$ & $0 \pm 0$ & $5 \pm 2$ & $59 \pm 11$ & $98 \pm 1$ & $5 \pm 4$ \\
\hline$M C$ & $85 \pm 4^{*}$ & $76 \pm 7^{*}$ & $29 \pm 8^{*}$ & $8 \pm 3$ & $97 \pm 1^{*}$ & $98 \pm 2$ & $3 \pm 2$ \\
\hline
\end{tabular}

The table displays the mean \pm SEM percentages of MSC-expressing surface markers HLA class I and II, PD-L1 and CD73, measured by flow cytometry , the mean \pm SEM concentration of L-Kynurenine $[\mu \mathrm{M}]$ and $\mathrm{PGE}_{2}[\mathrm{ng} / \mathrm{ml}]$ measured by ELISA and fold increases in IL1RA mRNA expression compared to unstimulated MSC. $n=5$ uCMSC umbilical cord-derived mesenchymal stromal cells, $H L A$ human leukocyte antigen, IDO indoleamine 2,3 dioxygenase, $P G E_{2}$ prostaglandin $E_{2}, P D-L 1$ programmed cell death ligand 1, IL interleukin, IFN- $\gamma$ interferon gamma, IFN- $\beta$ interferon beta, TGF $\beta$ transforming growth factor beta, Starv starvation, Vit $B_{6}$ Vitamin $\mathrm{B}_{6}$, pyridoxal hydrochloride, $R A$ retinoic acid, $M C$ multiple cytokine combination

*ndicates $p<0.05$ 
Cy7, BD Biosciences, San Jose, CA, USA), CD73 (PE, BD Pharmingen, San Diego, CA, USA), CD90 (APC, R\&D Systems) and CD105 (FITC, R\&D Systems), hematopoietic markers CD31 (PB, BD Biosciences), CD45 (APC-Cy, BD Biosciences) and the surface markers: HLA class I (Pacific Blue, Biolegend, San Diego, CA, USA), HLA class II (PERCP, BD Biosciences), CD362 (APC, R\&D Systems), PD-L1 (PE, Biolegend), CD271 (PE-Cy7, BD Pharmingen), CD73 (PE, BD Pharmingen) and CD40 (PERCP, Biolegend).

\section{L-Kynurenine assay}

IDO activity was analysed by measuring L-Kynurenine levels in the supernatants. Supernatant was harvested at day 3 and centrifuged for 10 minutes at $3000 \mathrm{rpm}$, to remove dead cells. Samples were stored at $-80{ }^{\circ} \mathrm{C}$ until the assay was performed. After thawing, samples were spun down, at $3000 \mathrm{rpm}$ for 10 minutes. Subsequently, $100 \mu \mathrm{L}$ $30 \%$ trichloroacetic acid (TCAA) was added to $200 \mu \mathrm{L}$ sample, this was then vortexed and placed in a $50{ }^{\circ} \mathrm{C}$ waterbath for 30 minutes. The tubes were then centrifuged at 12,000 rpm for 5 minutes. A total of $75 \mu \mathrm{L}$ supernatant was added to $75 \mu \mathrm{L}$ Ehrlich reagent, in duplicate, and measured with a spectrophotometer (Victor 1420 Multilabel Plate Reader; LKB-Wallac, Turku, Finland) at an absorbance of $490 \mathrm{~nm}$.

\section{$\mathrm{PGE}_{2}$ ELISA}

$\mathrm{PGE}_{2}$ secretion by ucMSC was analysed in ucMSC culture supernatant with the $\mathrm{PGE}_{2}$ High-sensitivity ELISA Kit according to the manufacturer's instructions (Enzo Life Sciences BVBA, Antwerp, Belgium, ADI-930-001).

\section{RT-PCR}

UcMSC were seeded at 100,000 cells/well in 6-well plates and stimulated with the various factors. At day 3 , supernatant was removed and cells were washed with phosphate-buffered saline (PBS), RNA (Life Technologies) was added later and the plates placed in the fridge. The next day, mRNA was isolated with the use of the High Pure RNA Isolation Kit (Roche Diagnostics, Basel, Switzerland). mRNA was isolated from liver slices using Trizol reagent (Invitrogen, Life Technologies, Carlsbad, CA, USA). cDNA was synthesized from 500 ng mRNA with random primers (Promega Benelux B.V., The Netherlands). Quantitative gene expression was determined using TaqMan Gene Expression Master Mix (Life Technologies) and assays-on-demand for IL-1RA (Hs00893626_m1), MCP-1 (Mm00441242_m1), IL-6 (Mm00446190_m1), TNF- $\alpha$ (Mm00443258_m1) and IP10 (Mm00445235_m1). GAPDH (Hs 99999905_m1) was used as housekeeping gene for analysing gene expression of ucMSC. Data was expressed as the gene expression relative to GAPDH and comparing fold changes to the untreated MSC. Gene expression levels of the liver slices are expressed as copy numbers (efficiency ${ }^{-\Delta \mathrm{Ct}}$ ).

\section{Isolation of PBMC}

Peripheral blood samples were collected from living kidney donors at Erasmus $\mathrm{MC}$ or isolated from buffy coats obtained from Sanquin Blood Bank (Amsterdam, Netherlands). Peripheral blood mononuclear cells (PBMC) were isolated by density gradient centrifugation, using Ficoll-Paque (GE Healthcare, Chicago, IL, USA) and frozen at $-180{ }^{\circ} \mathrm{C}$ until use.

\section{CD107a NK cytotoxicity assay}

For generation of activated NK cells, PBMCs were thawed, washed and seeded at 100,000 cells/well in 96well plates. They were cultured in RPMI 1640 medium (Life Technologies) with $1 \%$ penicillin/streptomycin solution $(\mathrm{P} / \mathrm{S} ; 100 \mathrm{IU} / \mathrm{ml}$ penicillin, $100 \mathrm{IU} / \mathrm{ml}$ streptomycin; Lonza), 10\% heat-inactivated FBS (Lonza), interleukin-2 (IL-2, $2.10^{2} \mathrm{IU} / \mathrm{ml} ; \quad$ Peprotech) and interleukin-15 (IL-15, $10 \mathrm{ng} / \mathrm{ml}$; Peprotech). At day 7, cells were collected and washed and NK cells were isolated using a negative selection MACS procedure (NK Cell Isolation Kit, human; MACS Miltenyi Biotec). Following MACS and a washing step, the cells were left overnight at $37{ }^{\circ} \mathrm{C}$ in a polystyrene tube with IL-2 and IL-15.

MACS-sorted NK cells were added to pre-treated ucMSC at a 4:1 ratio for 1 hour at $37^{\circ} \mathrm{C}$, together with monensin $(0.1 \mu \mathrm{L} / 200 \mu \mathrm{L} /$ well; $\mathrm{BD}$ Golgistop; $\mathrm{BD}$ Biosciences) and $\alpha$ CD107a antibody (LAMP-1, APC, BD Pharmingen) in polypropylene tubes. The cells were then washed and stained for CD3 (PERCP; BD Biosciences), CD16 (PE; BD Biosciences) and CD56 (PE; BD Biosciences) for 30 minutes at $4{ }^{\circ} \mathrm{C}$. The cells were subsequently washed and analysed with the FACSCanto II flow cytometer.

\section{T cell proliferation assay}

Pre-treated ucMSC were seeded into 96-well plates and left overnight to adhere in the incubator. The next day, PBMC were labelled with Cell Trace CFSE (Life Technologies) according to the instructions of the manufacturer and seeded on top of the ucMSC, at different [MSC:PBMC] ratios: [1:10], [1:5] and [1:2.5]. $\alpha \mathrm{CD} 3 /$ $\mathrm{CD} 28$ stimulation was added $(0.5 \mathrm{ug} / \mathrm{ml} \alpha \mathrm{CD} 3$ antibody, $0.5 \mu \mathrm{g} / \mathrm{ml} \alpha \mathrm{CD} 28$ antibody and $0.5 \mu \mathrm{g} / \mathrm{ml}$ goat- $\alpha$-mouse antibody; Life Technologies). The co-cultures were left for 3 days and PBMC were collected. PBMC were stained for CD4 (APC; eBioscience, San Diego, CA, USA), CD8 (Pe-cy7; eBioscience) and intracellular IFN- $\gamma$ (Bv421; BD Biosciences). With the use of the FACSCanto II flow cytometer the proliferation of PBMCs was measured. 


\section{Carbon tetrachloride $\left(\mathrm{CCl}_{4}\right)$ liver injury model}

Healthy 8-week-old male C57BL/6 mice were purchased from Charles River (Sulzfeld, Germany). The mice were housed in a facility with a 12-hour light-dark cycle and allowed free access to food and water. All the procedures and animal housing conditions were carried out in strict accordance with current EU legislation on animal experimentation and were approved by the Institutional Committee for Animal Research (DEC protocol EMC No. 127-12-14).

In the first set of experiments mice received either intraperitoneal (IP) $\mathrm{CCl}_{4}$ solution $(4 \mu \mathrm{l} / \mathrm{g}$ bodyweight, $250 \mu \mathrm{l} / \mathrm{ml}$ mineral oil; 289116 Sigma-Aldrich) or mineral oil for controls. Three hours after $\mathrm{CCl}_{4}$ injection pretreated ucMSC, which were labelled with Qtracker beads, were infused intravenously (IV) in the tail vein in $200 \mu \mathrm{l}$ suspension in PBS (250,000 cells/mice). Four hours after ucMSC infusion, mice were sacrificed using cardiac puncture under isoflurane anaesthesia (Additional file 3: Figure $\mathrm{S} 2$ for experimental regimen). Whole mice were embedded in mounting medium for cryotomy (O.C.T. compound; VWR Chemicals, Radnor, PA, USA) and put in liquid nitrogen until frozen. The whole mice were then stored at $-80{ }^{\circ} \mathrm{C}$ until shipment to BioInVision (Cleveland, OH, USA) for imaging.

In the second set of experiments, mice receiving IP $\mathrm{CCl}_{4}$ solution had a similar infusion of pre-treated ucMSC 3 hours later. After 72 hours the mice were sacrificed by cervical dislocation and blood and livers were harvested and frozen until further use.

\section{ALT measurement}

Serum samples were thawed and centrifuged at $3000 \mathrm{rpm}$ for 10 minutes. Thereafter, $50 \mu \mathrm{l}$ of sample was diluted 1:5 with MilliQ. ALT quantification was done with an ALT measurement kit according to the instructions of the manufacturer (Roche Diagnostics; 04467388190). The samples were measured using a Roche/Hitachi cobas c analyzer.

\section{Labelling, quantification and visualization of MSC}

Pre-treated ucMSC were collected using 0.05\% trypsinEDTA (Life Technologies) and washed. Subsequently they were labelled with Qtracker 605 cell labeling kit beads according to the manufacturer's instructions (Life Technologies). UcMSC take up Qtracker 605 beads during the labelling procedure. Post labelling, ucMSC were washed to remove any beads that were not internalized by the ucMSC.

Three-dimensional anatomical and molecular fluorescence videos were generated of the frozen whole mice samples by BioInVision Inc. with $\mathrm{CryoViz}^{\mathrm{Tm}}$ technology. The CryoViz ${ }^{\text {TM }}$ technology picks up the signal of clusters of Qtracker 605 beads, which are internalized in the
ucMSC. Cell counts were quantified using imaging algorithms.

\section{Ex vivo culture of liver slices}

Mouse livers were obtained from healthy $\mathrm{C} 57 \mathrm{Bl} / 6$ mice. Directly after isolation, mouse livers were sliced into $150 \mu \mathrm{m}$ thick slices with a diameter of $1 \mathrm{~cm}$ with Vibratome (VT 1200S, Leica Biosystems, Wetzlar, Germany). The slices were subsequently placed in 6-well plates containing differently pre-treated MSC in high-glucose DMEM with 10\% serum, Additional file 4: Figure S3. In addition, lipopolysaccharide [(LPS), $0.2 \mu \mathrm{g} / \mathrm{ml}$; SigmaAldrich] was added to the medium. The tissues were kept overnight at $37{ }^{\circ} \mathrm{C}, 5 \% \mathrm{CO}_{2}$ and $20 \% \mathrm{O}_{2}$ on a shaker $(50 \mathrm{rpm})$. After 24 hours, supernatant was collected and the liver slices were snap frozen.

\section{Milliplex assay}

Serum and tissue culture supernatant levels of IL-6, IL10 , granulocyte colony-stimulating factor (G-CSF), interferon gamma-induced protein 10 (IP-10), keratinocyte chemoattractant chemokine (C-X-C motif) ligand 1 (KC, CXCL1), monocyte chemoattractant protein-1 (MCP-1, also known as CCL2), macrophage inflammatory protein-1 alpha (MIP-1 $\alpha$ ) and tumour necrosis factor alpha (TNF- $\alpha$ ) were measured using a Milliplex mouse cytokine/chemokine magnetic bead panel multiplex assay (Merck Millipore, Billerica, MA, USA) and Mouse Premixed Multi-Analyte kit (Magnetic Luminex assay; cat LXSAMSM; R\&D Systems). The samples were measured on the Luminex 100/200 cytometer (Luminex, Austin, TX, USA) using Xponent software.

\section{Statistical analysis}

Data were analysed using IBM SPSS Statistics 21 (IBM Corp., Armonk, NY, USA) and Prism software v5.04 (GraphPad Software Inc., La Jolla, CA, USA), herein Mann-Whitney tests were performed. $P$ values $<0.05$ were considered significant.

\section{Results}

\section{Characterization of ucMSC}

Flow cytometric analysis of ucMSC demonstrated expression of CD13, CD73, CD90 and CD105 and absence of CD31 and CD45 (Additional file 5: Figure S4). This is in line with the minimal ISSCT criteria and thus confirming the MSC phenotype of the used cells.

\section{Impact of pre-treatment of ucMSC on immunogenicity and immunomodulatory phenotype}

To modulate the immunomodulatory and immunogenic phenotype of ucMSC in vitro, ucMSC were differentially treated for 3 days and the expression of key immunomodulatory and immunogenicity molecules was examined (Table 1). 
Expression of HLA class I and II on the ucMSC cell surface was used as a marker of ucMSC immunogenicity. The percentage of HLA class I-expressing ucMSC increased after treatment with IFN- $\gamma$ (8-fold; $p<0.05$ ), IFN- $\beta$ (5-fold; $p<0.05)$, Starv (2-fold; $p<0.05$ ), VitB 6 (7-fold; $p<0.05$ ), Starv + VitB 6 (9-fold; $p<0.05$ ), RA (4-fold; $p<0.05$ ) and MC (12-fold; $p<0.05)$ compared to untreated ucMSC. In addition, treatment with IFN- $\gamma, V_{i t B}, S t a r v+V_{i t B}$ and $\mathrm{MC}$ also increased the number of ucMSC expressing HLA class II by $7-(p<0.05), 3-(p<0.05), 2-(p<0.05)$ and 8 -fold $(p<0.05)$, respectively.

The number of ucMSC expressing the negative costimulatory molecule PD-L1 increased with IFN- $\gamma(96 \% \pm$ $3 ; p<0.05)$, Starv $+\operatorname{VitB}_{6}(72 \% \pm 1 ; p<0.05)$ and MC treatment $(97 \% \pm 1 ; p<0.05)$, compared to untreated ucMSC $(46 \% \pm 6)$. In addition, expression levels of PD-L1 per ucMSC were increased by IFN- $\gamma$ (median fluorescence intensity $(\mathrm{MFI})=1947 \pm 263 ; p<0.05)$, Starv $+\mathrm{VitB}_{6}(\mathrm{MFI}=$ $755 \pm 235 ; p<0.05)$ and MC treatment $(\mathrm{MFI}=1279 \pm 216$; $p<0.05$ ), with respect to untreated ucMSC (MFI $=219 \pm$ 22) (data not shown in Table 1). All treatments preserved the expression of CD73, which is involved in antiinflammatory adenosine production. Gene expression of IL1RA showed trends of upregulation after $\mathrm{VitB}_{6}$ treatment and the combined treatment of Starv + VitB 6 (67$(p<0.05)$, and 507 -fold increase $(p<0.05)$, respectively). IFN- $\gamma$ and MC treatment significantly upregulated IDO activity of ucMSC 14-fold $(p<0.05)$ and 15-fold $(p<0.05)$, respectively. IFN- $\gamma$ treatment significantly reduced the secretion of anti-inflammatory $\mathrm{PGE}_{2}$ compared to untreated MSC (14-fold; $p<0.05$ ).

Treatment with IL-7, IL-15, IL-17, budesonide, trespostinil, activin A and TNF- $\alpha$ showed no effect on any of these parameters (Additional file 2: Table S1) and thus the effects of these factors were not examined further.

\section{IFN- $\beta$, TGF $\beta$ and MC treatment of uCMSC protects against NK cell lysis}

To investigate the effect of pre-treatment of ucMSC on their susceptibility to NK cell lysis, the induction of CD107a expression on NK cells by ucMSC was analysed. The percentage of CD107a-expressing NK cells increased from $13 \% \pm 1$ to $62 \% \pm 4 \quad(p<0.05)$ when NK cells were exposed to untreated ucMSC (Fig. 1), however pre-treatment of ucMSC with IFN- $\beta$, TGF $\beta$ and MC reduced the increase in CD107a expression on NK cells to $45 \% \pm 1(p<0.05), 51 \% \pm 2(p<0.05)$ and $37 \% \pm 1$ $(p<0.05)$ respectively.

\section{Pre-treated MSC inhibit T cell proliferation and IFN- $\gamma$ production}

To examine the potential of MSC to inhibit CD4 and CD8 $\mathrm{T}$ cell proliferation and IFN- $\gamma$ production, $\alpha \mathrm{CD} 3 \mathrm{CD} 28$ activated PBMCs were co-cultured at different ratios with pre-treated ucMSC. CD4 and CD8 T cell proliferation was inhibited in a dose-dependent manner by all ucMSC (Fig. 2a/b). UcMSC treated with IFN- $\gamma$ and MC suppressed CD4 and CD8 $\mathrm{T}$ cell proliferation more potently than untreated MSC (Fig. 2a/b). However, none of the pre-treated ucMSC was able to significantly reduce the intracellular IFN- $\gamma$ content of CD4 and CD8 T cells, compared to the untreated MSC (Fig. 2c/d).

Effect of ucMSC in $\mathrm{CCl}_{4}$-induced liver inflammation model To examine the immunomodulatory capacity of pretreated ucMSC in $\mathrm{CCl}_{4}$-treated mice, serum levels of inflammatory associated cytokines MCP-1 and IP-10 were measured 3 days after cell infusion (Fig. 3a/b). Whilst significantly elevated levels were observed when comparing healthy to liver-injured mice, no significant differences were observed with ucMSC infusion. Similarly, infusion of pre-treated ucMSC did not reduce ALT levels as a marker of liver damage with respect to the $\mathrm{CCL}_{4}$ control or compared to infusion with untreated ucMSC (Fig. 3c). As no immunomodulation was observed; biodistribution of ucMSC was subsequently examined.

\section{Pre-treatment of ucMSC alters their retention and biodistribution in vivo}

UcMSC were labelled with Qtracker605 beads to enable analysis of their biodistribution at a single cell level by CryoViz imaging. Representative bright field and fluorescent images of ucMSC, 4 hours post labelling with Qtracker605 beads are shown in Fig. 3e. Four hours after infusion of 250,000 labelled ucMSC in $\mathrm{CCl}_{4}$-treated mice, $51 \%$ of untreated ucMSC were detectable within the mice (Fig. 3d/f). The majority of these ucMSC were located within the lungs $(81 \%)$ with a small percentage located within the liver (13\%) (Fig. 3g/h). Pre-treatment with MC (12\%) led to a significantly lower distribution of ucMSC to the lungs compared to untreated ucMSC (81\%) (Fig. 3g). Furthermore, a larger percentage of TGF $\beta$-treated MSC were found within mice (62\%) compared to untreated ucMSC, of which a larger percentage were found in the liver (25\%) compared to untreated ucMSC (13\%) (Fig. 3h). These observations were not a consequence of cell size differences as MC- and TGF $\beta$ treated ucMSC were the same size as untreated ucMSC (Additional file 6: Figure S5). Pre-treatment with IFN- $\gamma$, IFN- $\beta$, Starvation, VitB $_{6}$ and $M C$ resulted in the detection of lower numbers of ucMSC 4 hours after administration compared to untreated ucMSC (Fig. 3f).

\section{UcMSC(MC) resolve liver inflammation in an ex vivo liver tissue model}

As intravenously administered ucMSC poorly distribute to the liver, we assessed the efficacy of ucMSC in ameliorating liver inflammation in an ex vivo liver tissue slice, 


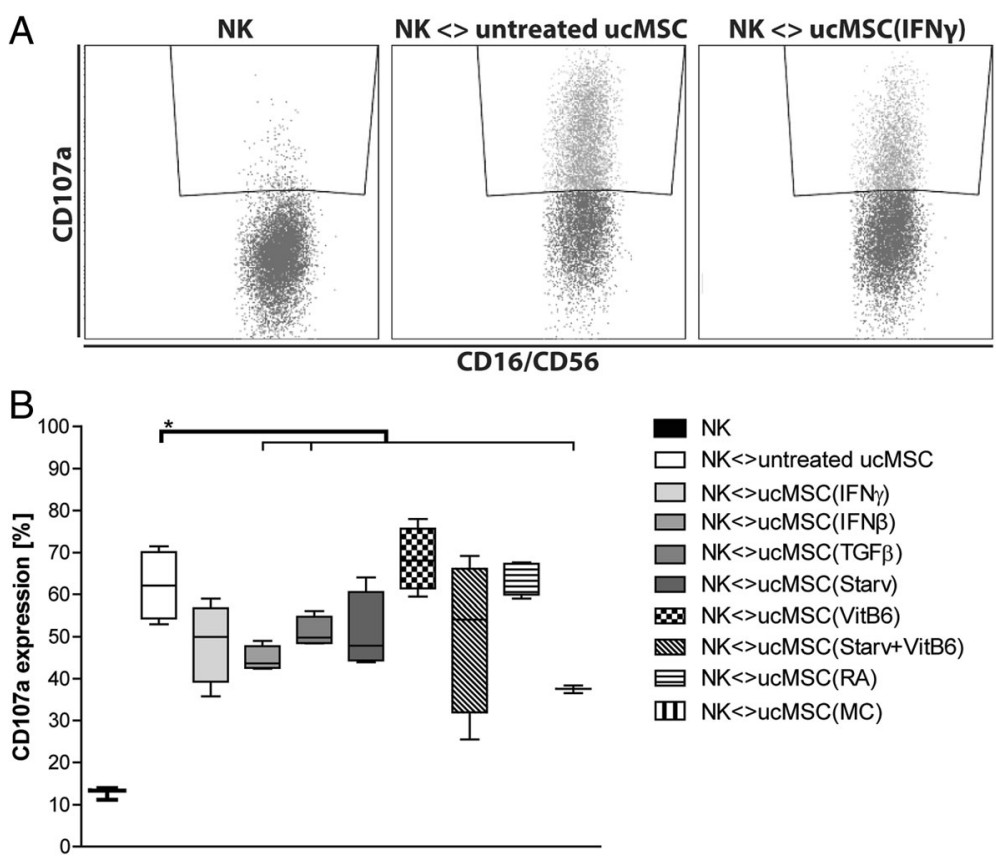

Fig. 1 CD107a-expressing NK cells after exposure to pre-treated uCMSC. a Representative FACS plots of CD107a expression on NK cells, without uCMSC (left), with untreated uCMSC (middle), with IFN- $\gamma$-treated uCMSC (right) b Graph displaying boxplots of CD107a-expressing NK cells after exposure to the various pre-treated MSC (untreated, IFN- $\gamma$, IFN- $\beta$, TGF $\beta$, starvation, vitamin $B_{6}$, Starv + VitB , $_{\text {, }}$ retinoic acid and combination IFN- $\gamma+$ TGF $\beta+R A(M C)$ ). Results are shown as means \pm SEM $(n=4)$. Indicates significant difference $(p<0.05)$. IFN- $\gamma$ interferon gamma, $M C$ multiple cytokine cocktail, NK natural killer cells, RA retinoic acid, Starv starvation, serum deprivation, TGF $\beta$ transforming growth factor beta, uCMSC umbilical cord-derived mesenchymal stromal cells, VitB $B_{6}$ vitamin $B_{6}$, pyridoxal hydrochloride

where cells were placed in direct contact with injured liver tissue. Significantly elevated gene expression levels and secretion levels of inflammatory factors (MCP-1, TNF- $\alpha$, IL-6, IP-10 and CXCL1) were observed in the diseased control liver tissue compared to the healthy control (Fig. 4). Pre-treatment of MSC with MC resulted in a marked reduction in expression levels of several inflammatory genes (MCP-1, TNF- $\alpha$ and IP-10), with more limited effects seen on TNF- $\alpha$ ( ucMSC(IFN- $\beta$ )) and IP10 (ucMSC(VitB 6 ), ucMSC(starvation) and ucMSC(RA)). Moreover, $\mathrm{MC}$ pre-treatment decreased secretion of MCP-1, TNF- $\alpha$, IL-6 and CXCL1 (all $p<0.05$ ), whereas RA pre-treatment only reduced TNF- $\alpha$ secretion.

\section{Discussion}

MSC have shown to be a promising cell type for treating various immune disorders in numerous disease models $[3,4,19,21,22]$, including clinical trials of patients with liver disease [7-13]. However, the immunosuppressive effects of MSC need to be induced by inflammatory stimulation, and MSC get trapped in the lungs after intravenous infusion and have a short in vivo survival time $[29,30]$. Therefore, to enhance their therapeutic efficacy, improvement of their immunomodulatory properties and immunogenicity is necessary. The present study demonstrates that ucMSC are responsive to a variety of treatments, including inflammatory factors, vitamins and serum-deprivation. Their responsiveness may be employed to improve the properties of ucMSC to generate cells with enhanced therapeutic efficacy.

In vitro experiments showed that treatment with IFN$\gamma$ or $\mathrm{MC}$, increases the immunosuppressive capacity of ucMSC. In addition, treatment with IFN- $\beta$, TGF $\beta$ and MC strongly decreases their susceptibility to lysis by NK cells. In vivo tracking results showed differential effects of the pre-treatments on the MSC's biodistribution and survival, where treatment with $\mathrm{VitB}_{6}$, Starv $+\mathrm{VitB}_{6}$ and $\mathrm{MC}$ ensured rapid clearance while treatment with TGF $\beta$ resulted in prolonged presence of ucMSC. No immunomodulatory effects were observed by pre-treated ucMSC in a $\mathrm{CCl}_{4}$ liver inflammation model, possibly due to the fact that the majority of the cells were trapped in the lungs. In the ex vivo culture system in which liver slices were cultured in the presence of ucMSC, significant amelioration of the inflammation by ucMSC(MC) was demonstrated by reduced inflammatory cytokine production. In summary, most effectively, pre-treatment of ucMSC with the multiple cytokine combination MC, resulted in enhanced immunomodulation and reduced immunogenicity.

Application of optimised ucMSC as an immunotherapy depends on the therapeutic requirements necessary to 

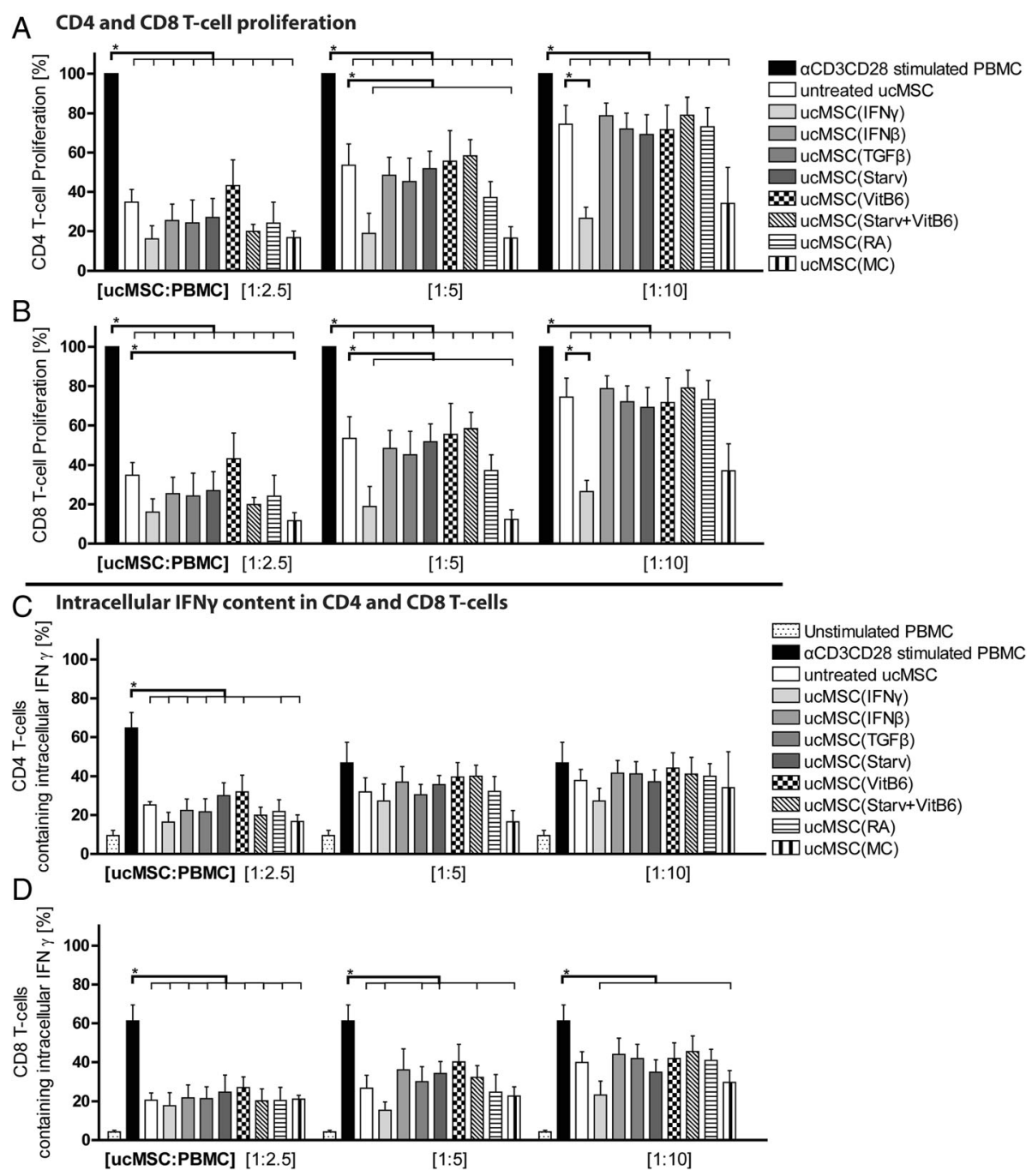

Fig. 2 Inhibition of CD4 and CD8 T cell proliferation and intracellular IFN- $\gamma$ production. MSC and aCD3CD28-stimulated and CSFE-labelled PBMCS were co-cultured at different ratios for 7 days. Thereafter proliferation of $\mathbf{a}$ CD4 and $\mathbf{b}$ CD8 T cells was measured utilizing CFSE dilution with FACS. Proliferation is expressed as the percentage of proliferating cells relative to the positive control in the absence of ucMSC. $\mathbf{c}$ IFN- $\gamma$ production by CD4 and $\mathbf{d}$ CD8 T cells was measured using FACS and an intracellular labelling of IFN- $\gamma$. The IFN- $\gamma$-containing CD4 and CD8 T cells are represented as a percentage from the CD4 or CD8 T cell population. Results are shown as means \pm SEM $(n=5)$. ${ }^{*}$ Indicates significant difference $(p<0.05)$. IFN- $\gamma$ interferon gamma, $M C$ multiple cytokine cocktail, $P B M C$ peripheral blood mononuclear cells, RA retinoic acid, Starv starvation, serum deprivation, TGF $\beta$ transforming growth factor beta, UCMSC umbilical cord-derived mesenchymal stromal cells, VitB ${ }_{6}$ vitamin $B_{6}$, pyridoxal hydrochloride

target the disorder. For example, strong immunomodulatory properties in MSC such as high IDO activity are favourable when helping graft acceptance after transplantation [19]. Secretion of PGE 2 and CCL2 has shown to be important to attenuate sepsis, local inflammation and mediates autoimmune disorders $[3,4,21,22]$. In the present study we observed that ucMSC are very susceptible to treatment by IFN- $\gamma$ and $\mathrm{MC}$, whereby they are induced into a strong immunomodulatory phenotype with high IDO activity, PD-L1 expression and potential to inhibit lymphocyte proliferation. Interestingly, in contrast to IFN- $\gamma$ treatment, MC treatment also decreases the susceptibility of ucMSC to NK cell lysis and ameliorates inflammation in liver tissue slices.

Our results demonstrate that the phenotype and function of ucMSC is not fixed. Recently, we observed that the lung microvasculature wherein MSC get trapped initiate upregulation of various pathways in MSC and thus alter their phenotype after infusion [42]. It is conceivable that the induced changes by the various pre-treatments will be influenced after infusion. The interactions between pre-treated ucMSC and the microenvironment are therefore a determinant on the effectiveness of these ucMSC. 

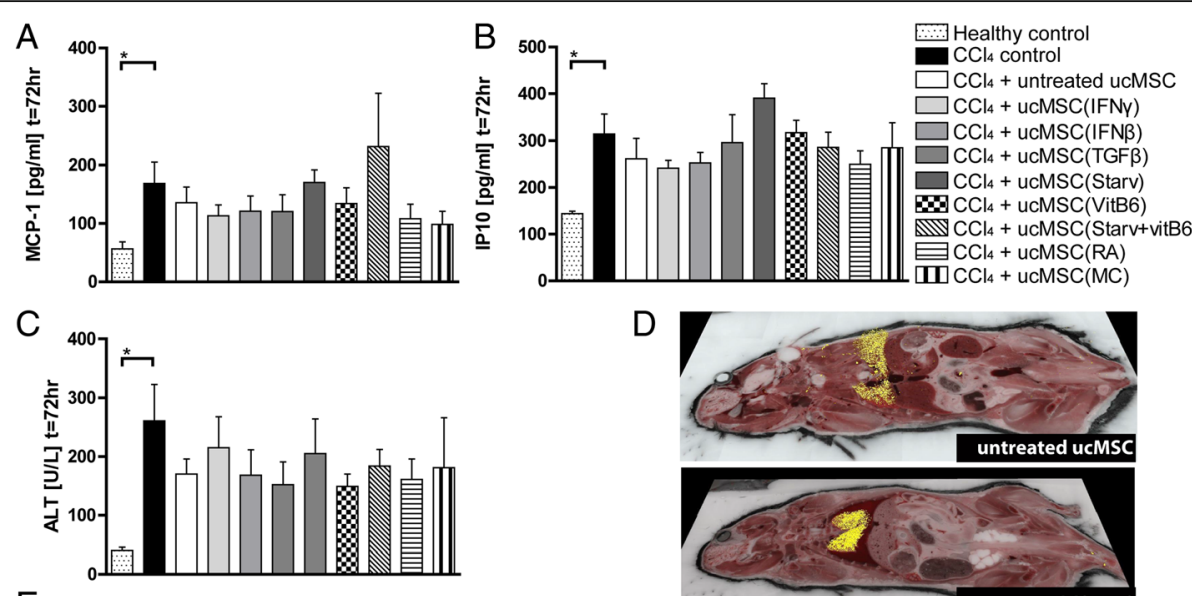

E
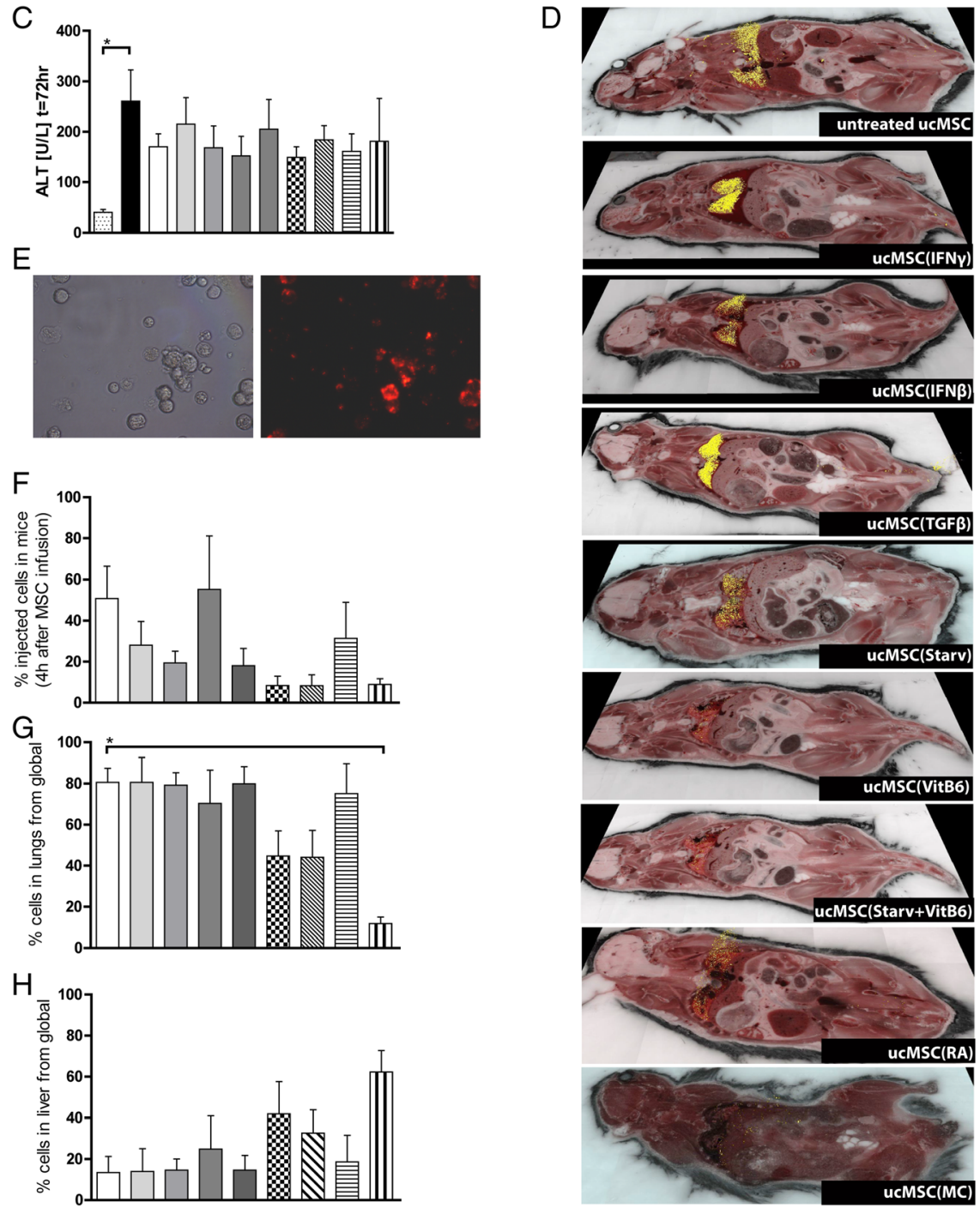

Fig. 3 Effects on inflammation and liver damage in $\mathrm{CCL}_{4}$-induced liver injury and biodistribution of pre-treated MSC. Pretreated MSC were labelled with fluorescent Qtracker 605 beads and intravenously infused in C57BL/6 mice. a Levels of MCP-1, b IP-10 and c ALT were measured in the serum 72 hours after UCMSC infusion. $\mathbf{d}$ Representative images of the biodistribution of pre-treated MSC in vivo 4 hours after ucMSC infusion. Yellow dots correspond with a cluster of observed MSC. e Representative image of ucMSC labelled with Qtracker 605 beads, still visible in MSC 4 hours after labelling. $\mathbf{f}$ Diagram showing the percentage of infused ucMSC 4 hours after administration. Figures $(\mathbf{g})$ and $(\mathbf{h})$ show the relative number of ucMSC in lungs and liver, respectively, calculated from the total number of detected ucMSC. Results are shown as means \pm SEM $(n=4)$. "Indicates significant difference $(p<0.05)$ with respect to the $\mathrm{CCL}_{4}$ control. ALT alanine aminotransferase, $C \mathrm{Cl}_{4}$ carbon tetrachloride, IFN- $y$ interferon gamma, $M C$ multiple cytokine cocktail, MCP-1 monocyte chemotactic protein-1, RA retinoic acid, Starv starvation, serum deprivation, TGF $\beta$ transforming growth factor beta, ucMSC umbilical cord-derived mesenchymal stromal cells, VitB $B_{6}$ vitamin $B_{6}$, pyridoxal hydrochloride

Efficacy of MSC therapy depends on various aspects, one of which is the biodistribution of MSC after infusion. Although no direct correlation has been established, it is suggested that short-term effects of MSC are mediated by their secretome and their long-term effects are a result of activation and interaction with other cells types, via a hit- 


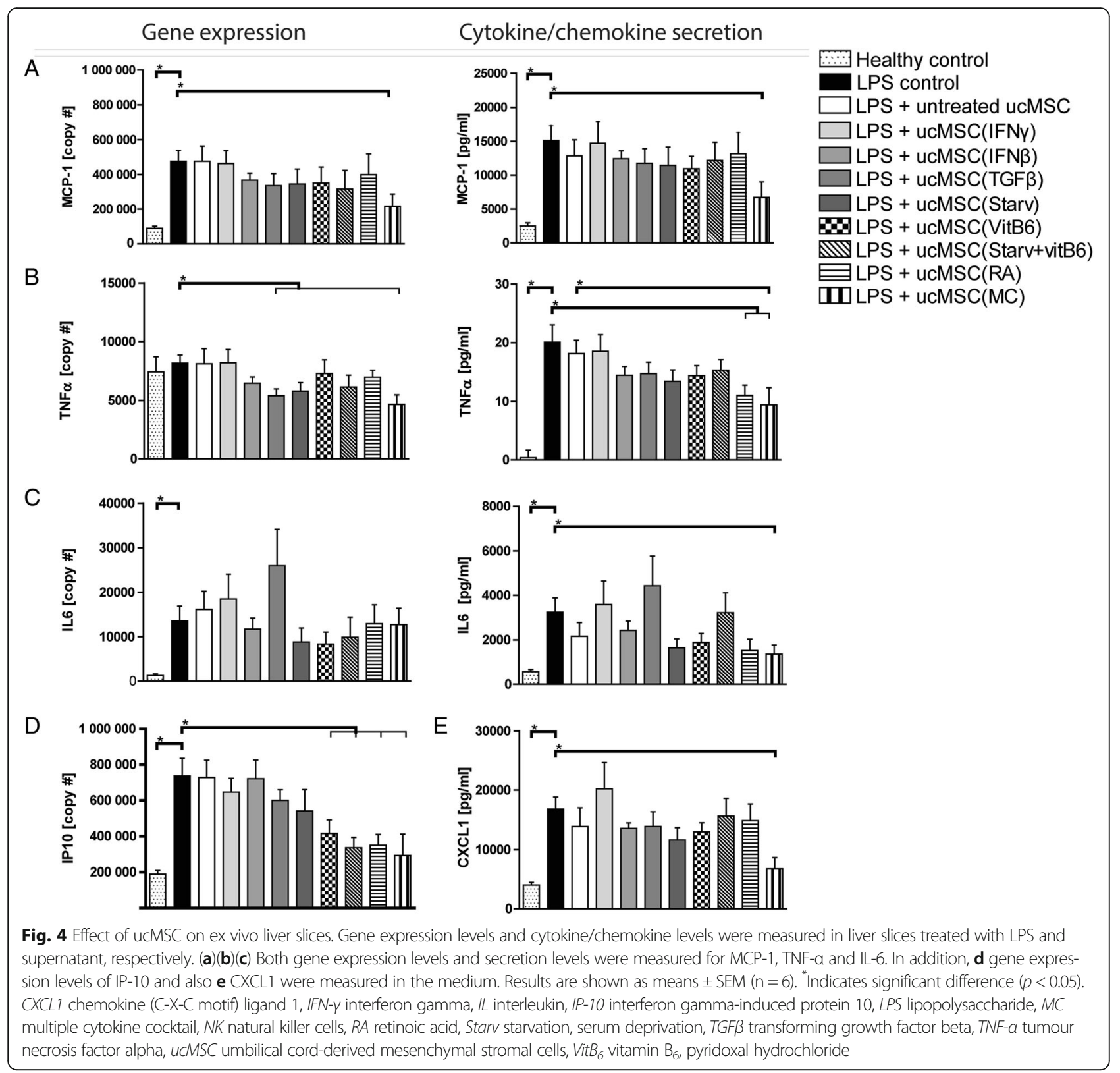

and-run mechanism $[3,15,18,21,43]$. Thus, the biodistribution of MSC determines which cell types they may encounter and depending on the aim of the therapy a specific distribution will be favoured. Tracking of labelled ucMSC by CryoViz enables in-depth visualization of MSC after administration and subsequently gives an interpretation of not only their biodistribution, but also their survival. Previously, localization in the lungs and short survival time of intravenously injected bone marrowderived MSC was observed [29]. The present study confirms that the majority of infused ucMSC accumulate in the lungs and that there is a rapid clearance of cells. The retainment of ucMSC was improved by pre-treatment with TGF $\beta$, which corresponds with the observed reduced recognition of ucMSC(TGF $\beta$ ) by NK cells in vitro. Interestingly, ucMSC(TGF $\beta$ ) showed no differences in their expression of HLA type I and II whereas they were less recognized less by NK cells. This suggests that TGF $\beta$ potentially modulates the expression of ligands on MSC that were not analysed in this study (e.g. NKG2D, DNAM1 and natural cytotoxicity receptors [44-46]). Depending on the therapeutic requirements, longevity or rapid clearance of administered MSC may be desirable. Our results demonstrate that longevity and biodistribution of MSC can be modulated by pre-treatment of the cells.

Lack of immunomodulation by any of the pre-treated ucMSC in vivo could be credited to the fact that the ucMSC were unable to travel towards the liver. As for 
when the cells were in contact with targeted liver tissue, in the inflammatory ex vivo model, strong amelioration of the inflammation by ucMSC(MC) was observed. Possibly, this in vivo inflammatory liver model requires ucMSC to be in direct contact with the tissue for them to be able to exert their immunomodulatory capacities. Therefore for future studies, administration of ucMSC via the portal vein or hepatic artery may be a more efficient approach for treatment of liver inflammation.

\section{Conclusions}

To conclude, these findings demonstrate that ucMSC are responsive to in vitro treatment, whereby their immunomodulatory properties and their immunogenicity can be differentially modulated. TGF $\beta$ treatment of ucMSC reduced their immunogenicity and altered their biodistribution and IFN $-\gamma$ treatment enhanced their immunomodulatory capacities. Most interestingly, treatment with the multiple cytokine combination MC resulted in reduced immunogenicity, increased immunomodulatory capacity as well as enhanced effectiveness to ameliorate liver inflammation. Therefore, in vitro pre-treatment of ucMSC MC will make them more suitable as an effective immunotherapy targeted for liver inflammation.

\section{Additional files}

Additional file 1: Figure S1. Study design. This study is organized in three sections: in vitro, in vivo and ex vivo. (TIF $6664 \mathrm{~kb}$ )

Additional file 2: Table S1. Key immunogenic and immunomodulatory molecules after 3 days of in vitro treatment of ucMSC. The table displays the mean \pm SEM percentages of MSC expressing surface markers HLA class -I and -II, PD-L1 and CD73, measured via flow cytometric analysis. Mean \pm SEM concentration of L-Kynurenine $[\mu \mathrm{M}]$ and PGE2 $[\mathrm{ng} / \mathrm{ml}]$. Fold increase of IL1RA gene expression compared to unstimulated UCMSC. $n=5$, no significant differences were observed. (DOCX $17 \mathrm{~kb}$ )

Additional file 3: Figure S2. In vivo experimental schemes. (Top) In the first set of experiments mice were treated with $\mathrm{CCl}_{4}$ and 3 hours later pre-treated uCMSC (untreated, IFN- $\gamma$, IFN- $\beta$, TGF $\beta$, starvation, vitamin $B_{6}$, Starv + VitB 6 , RA and MC), which were labeled with Qtracker605 beads, were infused IV. Four hours after UCMSC infusion the mice were sacrificed and prepared for imaging. (Bottom) In the second set of experiments mice were sacrificed 72 hours after CCL4 injection and serum was collected. (TIF $7779 \mathrm{~kb}$ )

Additional file 4: Figure S3. Ex vivo experimental scheme. UcMSC were pre-treated for 3 days. Medium was then refreshed and the cells were left overnight in the incubator. The following day, livers were collected from healthy C57BL/6 mice and directly after isolation cut into slices (diameter $=1 \mathrm{~cm}$ and thickness $=150 \mu \mathrm{m}$ ) and placed in the wells on top of the pre-treated ucMSC in the presence of LPS. The liver slices were left overnight in the incubator on a shaker (50 rpm). After 24 hours, supernatant and liver slices were harvested. (TIF $4600 \mathrm{~kb}$ )

Additional file 5: Figure S4. Characterization uCMSC by flow cytometry. Representative histograms of expression of MSC markers CD13, CD73, CD90, CD105 and negative expression of the endothelial marker CD31 and hematopoietic marker CD45. Stained ucMSC (grey) and isotype control (white). (TIF $30000 \mathrm{~kb}$ )

Additional file 6: Figure S5. MSC diameter. Measured diameter of pre-treated ucMSC in micrometres. Results are shown as means \pm SEM $(n=5)$. IIndicates $p<0.05$. (TIF $4687 \mathrm{~kb})$

\section{Abbreviations}

ALT: Alanine transaminase; bFGF: Basic fibroblast growth factor; $\mathrm{CCl}_{4}$ : Carbon tetrachloride; CXCL1: Chemokine (C-X-C motif) ligand 1; FBS: Fetal bovine serum; HLA: Human leukocyte antigen; IDO: Indoleamine 2,3 dioxygenase; IFN-ү: Interferon gamma; IL: Interleukin; IP: Intraperitoneal; IP-10: Interferon gamma-induced protein 10; IV: Intravenous; LPS: Lipopolysaccharide; MC: Multiple cytokine cocktail; MCP-1: Monocyte chemotactic protein-1; MFI: Median fluorescence intensity; MSC: Mesenchymal stromal cells; NK: Natural killer cells; PBMC: Peripheral blood mononuclear cells; PBS: Phosphate-buffered saline; PD-L1: Programmed cell death ligand 1; $\mathrm{PGE}_{2}$ : Prostaglandin $\mathrm{E}_{2} ; \mathrm{RA}$ : Retinoic acid; Starv: Starvation, serum deprivation; TGF $\beta$ : Transforming growth factor beta; TNF-a: Tumour necrosis factor alpha; ucMSC: Umbilical cord-derived mesenchymal stromal cells; VitB 6 : Vitamin $B_{6}$, pyridoxal hydrochloride; $V_{i t}$ : Vitamin $\mathrm{D}_{3}, 1 \mathrm{a}, 25$-Dihydroxyvitamin

\section{Acknowledgements}

This project has received funding from the European Union's Seventh Framework Programme for Research, technological development and demonstration under grant agreement number 602363.

\section{Funding}

This project has received funding from the European Union's Seventh Framework Programme for Research, technological development and demonstration under grant agreement number 602363.

J.A.A. van Zoggel has received support from the Innovative Medicines Initiative Joint Undertaking under grant agreement number 115188 , resources of which are composed of financial contribution from the European Union's Seventh Framework Programme (FP7/2007-2013) and EFPIA companies' in-kind contribution (http://www.predect.eu/about/).

\section{Availability of data and materials}

The datasets used and/or analysed during the current study are available from the corresponding author on reasonable request.

\section{Authors' contributions}

SFHW and AMM contributed to collection of data, data analysis and interpretation and manuscript writing. MF contributed to conception and design. TS, JAAZ, SSK, FL and MG contributed to collection of data. LO'F contributed to manuscript writing. DR contributed: to collection of data. PNN and CCB contributed to administrative support. MJH contributed: to conception and design, data analysis and interpretation and manuscript writing. All authors read and approved the final manuscript.

\section{Competing interests}

The authors declare that they have no competing interests.

\section{Consent for publication}

Not applicable.

\section{Ethics approval and consent to participate}

Human umbilical cord tissue was collected from virally screened healthy donors by Tissue Solutions Ltd. (Glasgow, UK) (all cord tissues provided by Tissue Solutions are obtained according to the legal and ethical requirements of the country of collection, with the approval (reference number C.A. 9021. Isolation and purification of a stromal stem cell population from umbilical cord) of an ethics committee at Galway University Hospital (Clinical Research Ethics Committee (CREC)) and with anonymous consent from the donors).

Healthy donor blood samples were collected for the Biobank with consent from the participants, this was with the approval of the medical ethics committee of the Erasmus University Medical Center in Rotterdam, the Netherlands (MEC-2010-022). In addition peripheral blood samples were also isolated from buffy coats obtained from Sanquin Blood Bank with anonymous consent from the donors.

All procedures with animals and animal housing conditions were carried out in strict accordance with current EU legislation on animal experimentation and were approved by the Institutional Committee for Animal Research (DEC protocol EMC No. 127-12-14). 


\section{Publisher's Note}

Springer Nature remains neutral with regard to jurisdictional claims in published maps and institutional affiliations.

\section{Author details \\ Nephrology and Transplantation, Department of Internal Medicine, Erasmus MC, Postbus 20403000 CA Rotterdam, The Netherlands. 'Experimental Urology Department, Department of Internal Medicine, Erasmus MC, Rotterdam, The Netherlands. ${ }^{3}$ Orbsen Therapeutics Ltd, Galway, Ireland. ${ }^{4}$ National Institute for Health Research (NIHR) Birmingham Liver Biomedical Research Unit and Centre for Liver Research, University of Birmingham, Birmingham, UK. ${ }^{5}$ BiolnVision Inc, Mayfield Village, OH, USA}

Received: 24 March 2017 Revised: 12 May 2017 Accepted: 17 May 2017 Published online: 08 June 2017

\section{References}

1. Luk F, et al. Efficacy of immunotherapy with mesenchymal stem cells in man: a systematic review. Expert Rev Clin Immunol. 2015;11(5):617-36.

2. Gonzalez-Rey E, et al. Human adult stem cells derived from adipose tissue protect against experimental colitis and sepsis. Gut. 2009;58(7):929-39.

3. Bouffi $C$, et al. IL-6-dependent PGE2 secretion by mesenchymal stem cells inhibits local inflammation in experimental arthritis. PLoS One. 2010;5(12):e14247.

4. Rafei M, et al. Mesenchymal stromal cells ameliorate experimental autoimmune encephalomyelitis by inhibiting CD4 Th17 T cells in a CC chemokine ligand 2-dependent manner. J Immunol. 2009;182(10):5994-6002.

5. Le Blanc K, et al. Mesenchymal stem cells for treatment of steroid-resistant, severe, acute graft-versus-host disease: a phase II study. Lancet. 2008;371(9624):1579-86.

6. Forbes $\mathrm{GM}$, et al. A phase 2 study of allogeneic mesenchymal stromal cells for luminal Crohn's disease refractory to biologic therapy. Clin Gastroenterol Hepatol. 2014;12(1):64-71.

7. Zhang Z, et al. Human umbilical cord mesenchymal stem cells improve liver function and ascites in decompensated liver cirrhosis patients. $J$ Gastroenterol Hepatol. 2012;27 Suppl 2:112-20.

8. El-Ansary $M$, et al. Phase II trial: undifferentiated versus differentiated autologous mesenchymal stem cells transplantation in Egyptian patients with HCV induced liver cirrhosis. Stem Cell Rev Rep. 2012;8(3):972-81.

9. Amin MA, et al. Short-term evaluation of autologous transplantation of bone marrow-derived mesenchymal stem cells in patients with cirrhosis: Egyptian study. Clin Transplant. 2013;27(4):607-12.

10. Xu LM, et al. Randomized trial of autologous bone marrow mesenchymal stem cells transplantation for hepatitis B virus cirrhosis: regulation of Treg/ Th17 cells. J Gastroenterol Hepatol. 2014;29(8):1620-8.

11. Liu $X$, et al. Improvement in poor graft function after allogeneic hematopoietic stem cell transplantation upon administration of mesenchymal stem cells from third-party donors: a pilot prospective study. Cell Transplant. 2014;23(9):1087-98.

12. Shi $M$, et al. Human mesenchymal stem cell transfusion is safe and improves liver function in acute-on-chronic liver failure patients. Stem Cells Transl Med. 2012;1(10):725-31.

13. El-Ansary $M$, et al. Phase I Trial: Mesenchymal stem cells transplantation in end stage liver disease. Stem Cell. 2010;1(2):22-33.

14. Nauta AJ, Fibbe WE. Immunomodulatory properties of mesenchymal stromal cells. Blood. 2007;110(10):3499-506.

15. Soleymaninejadian E, Pramanik K, Samadian E. Immunomodulatory properties of mesenchymal stem cells: Cytokines and factors. Am J Reprod Immunol. 2012;67(1):1-8.

16. English $\mathrm{K}$, et al. Cell contact, prostaglandin E2 and transforming growth factor beta 1 play non-redundant roles in human mesenchymal stem cell induction of CD4 + CD25Highforkhead box P3+ regulatory T cells. Clin Exp Immunol. 2009;156(1):149-60.

17. Engela $\mathrm{AU}$, et al. On the interactions between mesenchymal stem cells and regulatory $T$ cells for immunomodulation in transplantation. Front Immunol. 2012;3:126.

18. Meisel $R$, et al. Human bone marrow stromal cells inhibit allogeneic T-cell responses by indoleamine 2,3-dioxygenase-mediated tryptophan degradation. Blood. 2004;103(12):4619-21.
19. Popp FC, et al. Mesenchymal stem cells can induce long-term acceptance of solid organ allografts in synergy with low-dose mycophenolate. Transpl Immunol. 2008;20(1-2):55-60.

20. Harris SG, et al. Prostaglandins as modulators of immunity. Trends Immunol. 2002;23(3):144-50

21. Nemeth $\mathrm{K}$, et al. Bone marrow stromal cells attenuate sepsis via prostaglandin E(2)-dependent reprogramming of host macrophages to increase their interleukin-10 production. Nat Med. 2009;15(1):42-9.

22. Rafei M, et al. Allogeneic mesenchymal stem cells for treatment of experimental autoimmune encephalomyelitis. Mol Ther. 2009;17(10):1799-803.

23. Luz-Crawford $P$, et al. Mesenchymal stem cell-derived interleukin 1 receptor antagonist promotes macrophage polarization and inhibits B cell differentiation. Stem Cells. 2016;34(2):483-92.

24. Augello A, et al. Bone marrow mesenchymal progenitor cells inhibit lymphocyte proliferation by activation of the programmed death 1 pathway. Eur J Immunol. 2005;35(5):1482-90.

25. Blanc $K L_{L}$, et al. HLA expression and immunologic properties of differentiated and undifferentiated mesenchymal stem cells. Exp Hematol. 2003;31(10):890-6.

26. Crop MJ, et al. Human mesenchymal stem cells are susceptible to lysis by CD8+ T cells and NK cells. Cell Transplant. 2011;20(10):1547-59.

27. Sotiropoulou PA, et al. Interactions between human mesenchymal stem cells and natural killer cells. Stem Cells. 2006;24(1):74-85.

28. Cho PS, et al. Immunogenicity of umbilical cord tissue derived cells. Blood. 2008;111(1):430-8.

29. Eggenhofer $E$, et al. Mesenchymal stem cells are short-lived and do not migrate beyond the lungs after intravenous infusion. Front Immunol. 2012;3:297.

30. Fischer UM, et al. Pulmonary passage is a major obstacle for intravenous stem cell delivery: the pulmonary first-pass effect. Stem Cells Dev. 2009;18(5):683-92.

31. da da Silva Meirelles L, Chagastelles PC, Nardi NB. Mesenchymal stem cells reside in virtually all post-natal organs and tissues. J Cell Sci. 2006;119:2204-13.

32. Kuci S, et al. CD271 antigen defines a subset of multipotent stromal cells with immunosuppressive and lymphohematopoietic engraftmentpromoting properties. Haematologica. 2010;95(4):651-9.

33. Campioni D, et al. A decreased positivity for CD90 on human mesenchymal stromal cells (MSCs) is associated with a loss of immunosuppressive activity by MSCs. Cytometry Part B Clin Cytometry. 2009;76(3):225-30.

34. Beavis PA, et al. CD73: a potent suppressor of antitumor immune responses. Trends Immunol. 2012;33(5):231-7.

35. Nasef A, et al. Selected Stro-1-enriched bone marrow stromal cells display a major suppressive effect on lymphocyte proliferation. Int J Lab Hematol. 2009;31(1):9-19.

36. Bensidhoum M, et al. Homing of in vitro expanded Stro-1- or Stro-1+ human mesenchymal stem cells into the NOD/SCID mouse and their role in supporting human CD34 cell engraftment. Blood. 2004;103(9):3313-9.

37. Prasanna SJ, et al. Pro-inflammatory cytokines, IFN(gamma) and TNF(alpha), influence immune properties of human bone marrow and Wharton jelly mesenchymal stem cells differentially. PLoS One. 2010;5(2):e9016.

38. Sivanathan $\mathrm{KN}$, et al. Interleukin-17A-induced human mesenchymal stem cells are superior modulators of immunological function. Stem Cells. 2015:33(9):2850-63.

39. de Witte SF, et al. Toward development of imesenchymal stem cells for immunomodulatory therapy. Front Immunol. 2015;6:648.

40. Roemeling-van Rhijn $M$, et al. Effects of hypoxia on the immunomodulatory properties of adipose tissue-derived mesenchymal stem cells. Front Immunol. 2013:4:203.

41. Dominici $M$, et al. Minimal criteria for defining multipotent mesenchymal stromal cells. The International Society for Cellular Therapy position statement. Cytotherapy. 2006:8(4):315-7

42. Hoogduijn MJ, et al. Effects of freeze-thawing and intravenous infusion on mesenchymal stromal cell gene expression. Stem Cells Dev. 2016;25(8):586-97.

43. Luz-Crawford $P$, et al. Mesenchymal stem cells generate a CD4 + CD25 + Foxp3+ regulatory $T$ cell population during the differentiation process of Th1 and Th17 cells. Stem Cell Res Ther. 2013:4(3):65.

44. Giuliani M, et al. Human mesenchymal stem cells derived from induced pluripotent stem cells down-regulate NK-cell cytolytic machinery. Blood. 2011:118(12):3254-62.

45. Poggi A, et al. Interaction between human NK cells and bone marrow stromal cells induces NK cell triggering: role of NKp30 and NKG2D receptors. J Immunol. 2005;175(10):6352-60

46. Gotherstrom $\mathrm{C}$, et al. Fetal and adult multipotent mesenchymal stromal cells are killed by different pathways. Cytotherapy. 2011;13(3):269-78. 